Keywords:

ICP-MS, ICP-ES, Rare Earth

Resin, ICD Limits

Retention: Permanent

\title{
Application of Column Extraction Method for Impurities Analysis on HB-Line Plutonium Oxide in Support of MOX Feed Product Specifications
}

M.A. Jones

D.P. DiPrete

B.J. Wiedenman

March 2012

Savannah River National Laboratory Savannah River Nuclear Solutions, LLC Aiken, SC 29808

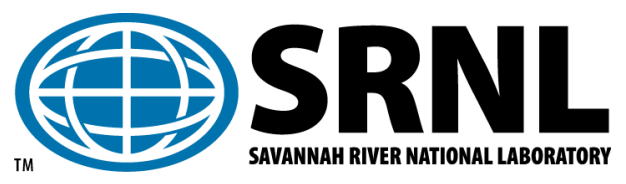


SRNL-STI-2012-00148

Revision 0

\section{DISCLAIMER}

This work was prepared under an agreement with and funded by the U.S. Government. Neither the U.S. Government or its employees, nor any of its contractors, subcontractors or their employees, makes any express or implied:

1. warranty or assumes any legal liability for the accuracy, completeness, or for the use or results of such use of any information, product, or process disclosed; or

2. representation that such use or results of such use would not infringe privately owned rights; or

3. endorsement or recommendation of any specifically identified commercial product, process, or service.

Any views and opinions of authors expressed in this work do not necessarily state or reflect those of the United States Government, or its contractors, or subcontractors.

\section{Printed in the United States of America \\ Prepared for \\ U.S. Department of Energy}




\section{REVIEWS AND APPROVALS}

AUTHORS:

\begin{tabular}{lc}
\hline M.A. Jones, Analytical Development, SRNL & Date
\end{tabular}

\begin{tabular}{ll}
\hline D.P. DiPrete, Analytical Development, SRNL Date & D
\end{tabular}

\begin{tabular}{ll}
\hline B.J. Wiedenman, Analytical Development, SRNL & Date
\end{tabular}

TECHNICAL REVIEW:

M.L. Crowder, Separations and Actinide Science Programs, SRNL Date

E.A. Kyser, Separations and Actinide Science Programs, SRNL Date

APPROVAL:

C.M. Gregory, Manager

Date

Spectroscopy and Separations, Analytical Development

S.D. Fink, Manager

Date

Separations and Actinide Science Programs 
SRNL-STI-2012-00148

Revision 0

\section{ACKNOWLEDGEMENTS}

The authors would like to acknowledge Loretta Farrow, Steve Moody, and Eugenia Robbins. 
SRNL-STI-2012-00148

Revision 0

This page intentionally left blank. 


\section{TABLE OF CONTENTS}

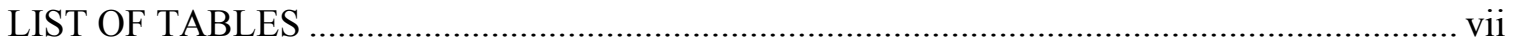

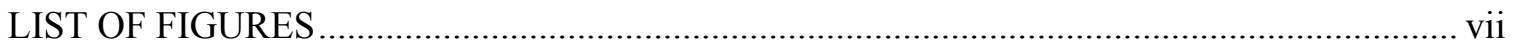

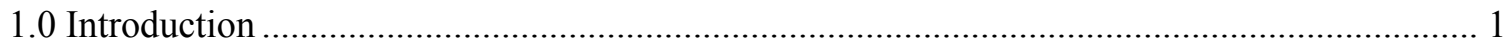

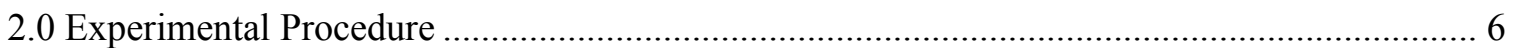

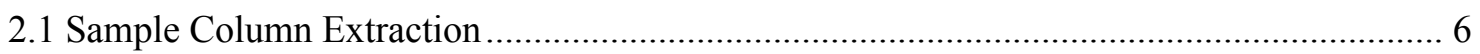

2.2 Spiked Sample Column Extraction .................................................................................. 7

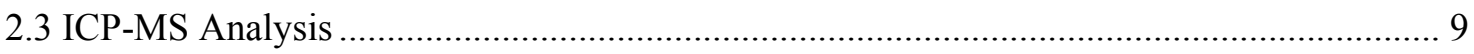

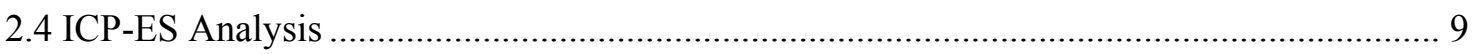

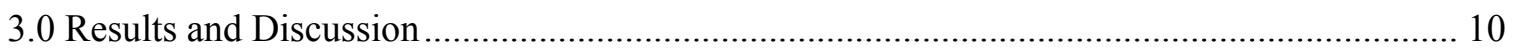

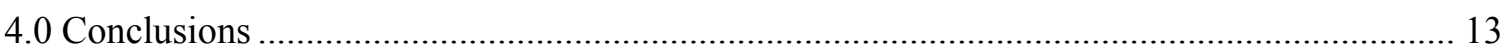

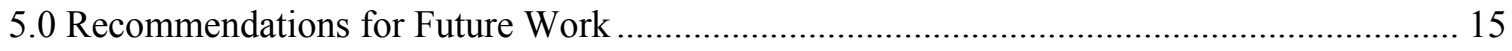

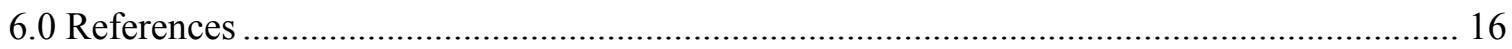




\section{LIST OF TABLES}

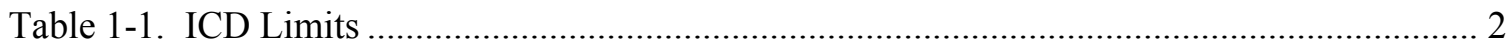

Table 1-2. Analtytical MRLs for "Dilute and Shoot" on $50 \mathrm{~g} / \mathrm{L}$ Pu Solution ................................ 4

Table 2-1. HP Standard Elements and Collection Steps …..................................................... 8

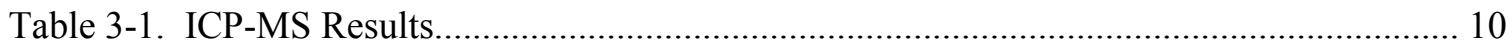

Table 3-2. ICP-MS Results in the Eluent Corrected for Nd Tracer.............................................. 11

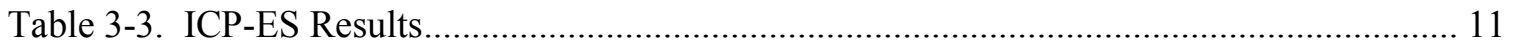

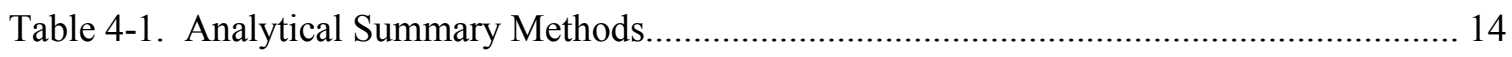

\section{LIST OF FIGURES}

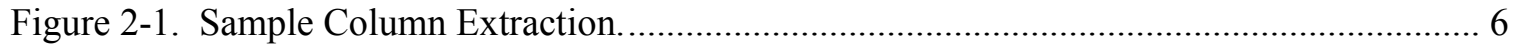

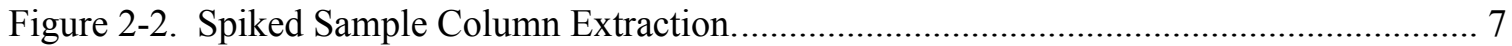




\section{LIST OF ABBREVIATIONS}

$\begin{array}{ll}\text { AA } & \text { Atomic Absorption } \\ \text { ADS } & \text { Analytical Development Section } \\ \text { AFS-2 } & \text { Alternate Feedstocks 2 } \\ \text { DF } & \text { Dilution Factor } \\ \text { EPA } & \text { Environmental Protection Agency } \\ \text { HP } & \text { High Purity } \\ \text { ICD } & \text { Interface Control Document } \\ \text { ICP-ES } & \text { Inductively Coupled Plasma - Emission Spectroscopy } \\ \text { ICP-MS } & \text { Inductively Coupled Plasma - Mass Spectrometry } \\ \text { IC } & \text { Ion Chromatography } \\ \text { IDL } & \text { Instrument Detection Level } \\ \text { IRL } & \text { Instrument Reporting Limit } \\ \text { MRL } & \text { Method Reporting Limit } \\ \text { MOX } & \text { Mixed Oxide } \\ \text { PPB } & \text { Parts-per-billion } \\ \text { PPT } & \text { Parts-per-trillion } \\ \text { RE } & \text { Rare Earth } \\ \text { SRNL } & \text { Savannah River National Laboratory }\end{array}$


SRNL-STI-2012-00148

Revision 0

\subsection{Introduction}

The current mission at H-Canyon involves the dissolution of an Alternate Feedstocks 2 (AFS-2) inventory that contains plutonium metal. Once dissolved, HB-Line is tasked with purifying the plutonium solution via anion exchange, precipitating the $\mathrm{Pu}$ as oxalate, and calcining to form plutonium oxide $\left(\mathrm{PuO}_{2}\right)$. The $\mathrm{PuO}_{2}$ will provide feed product for the Mixed Oxide (MOX) Fuel Fabrication Facility, and the anion exchange raffinate will be transferred to H-Canyon. ${ }^{1,2}$

The purity of the plutonium anion exchange product is essential for a successful MOX campaign. Consequently, HB-Line requests the development of an anion exchange flowsheet by the Savannah River National Laboratory (SRNL) that meets Interface Control Document (ICD) limits for the MOX Fuel Fabrication Facility (see Table 1-1). ${ }^{3}$ As noted in Table 1-1, the limits are divided into three columns; column B, column A, and exceptional, where column B lists the lowest required reporting limits in $\mu \mathrm{g} / \mathrm{g} \mathrm{Pu}$ for the elements of interest.

The SRNL Analytical Development section (ADS) is tasked with proving that reporting limits from their analytical methods meet these ICD limits for trace impurity levels. Included on Table 1-1 are the preferred AD methods for each element, where a bulk of the analyses is from the Inductively Coupled Plasma Emission Spectroscopy (ICP-ES) and Mass Spectrometry (ICP-MS) methods. The other method is Ion Chromatography (IC) for Cl and F. Most of the ICP-ES and ICP-MS analytes are routinely measured using guidance from technical procedures ADS- 1543 for ICP-MS ${ }^{4}$ and ADS-1573 for ICP-ES. ${ }^{5}$ Ga and V, however, are not routinely measured on AD's ICP-MS method and required method development for the scope of this paper. Am and Np are semi-quantified on the ICP-MS. A method is not currently set up for Bi and In, as they are used as internal standards for the ICP-MS method.

It should be noted that the reporting limits are requested for loading tests of up to $80 \mathrm{~g} \mathrm{Pu} / \mathrm{L}$. $^{1}$ Recent Pu measurements of the 13620B solution and January "Hearts Cut" sample submitted by the Separations and Actinides Science Program group respectively showed $45 \mathrm{~g} / \mathrm{L}$ and $50 \mathrm{~g} / \mathrm{L} \mathrm{Pu}-$ 239 on the ICP-MS method. The high Pu content in these samples imposes analytical matrix effects especially when performing a minimal dilution factor (DF) on ICP-ES and ICP-MS in an effort to meet the Column B limits. These matrix effects are both spectral and non-spectral. In the case of ICP-ES, Pu emission lines cause spectral interferences on analytical wavelengths of interest, and for ICP-MS, Pu forms doubly-charged species at lower masses and isobaric spectral interferences on surrounding masses (e.g., U-238). While spectral matrix effects are corrective to some extent (but with difficulty) for both methods, the non-spectral effects are deleterious, since they are due to the high $\mathrm{Pu}$ present through the sample introduction system and ultimately in the plasma. In this instance, a high level of $\mathrm{Pu}$ from a low dilution factor in the plasma hinders the ICP's efficiency as an ion source for other analytes, especially when they are at trace levels. With the application of an internal standard, a significant suppression or enhancement in signal recovery is observed when compared with the calibration standards, subsequently diminishing the data quality and causing instrument drift. 
Table 1-1. ICD Limits.

\begin{tabular}{|c|c|c|c|c|}
\hline $\begin{array}{c}\text { Chemical } \\
\text { Component }\end{array}$ & AD Method & B ( & $\mathbf{A}(\mu \mathrm{g} / \mathrm{g} \mathbf{P u})$ & $\begin{array}{c}\text { Exceptional } \\
(\mu \mathrm{g} / \mathrm{g} \mathrm{Pu})\end{array}$ \\
\hline $\mathrm{Al}$ & ICP-ES & 100 & 500 & 10000 \\
\hline B & ICP-ES & 1 & 100 & 1000 \\
\hline $\mathrm{Be}$ & ICP-ES & 100 & 100 & 2000 \\
\hline $\mathrm{C}$ & Not available & 500 & 1000 & 5000 \\
\hline $\mathrm{Ca}$ & ICP-ES & 150 & 500 & 10000 \\
\hline $\mathrm{Cd}$ & ICP-MS & 5 & 10 & 1000 \\
\hline $\mathrm{Cr}$ & ICP-ES & 200 & 1000 & 1500 \\
\hline $\mathrm{Cu}$ & ICP-ES & 100 & 100 & 500 \\
\hline $\mathrm{Fe}$ & ICP-ES & 500 & 2000 & 3000 \\
\hline $\mathrm{Ga}$ & ICP-MS & 0.12 & 12000 & 12500 \\
\hline $\mathrm{K}$ & ICP-ES & 100 & 300 & 10000 \\
\hline $\mathrm{Li}$ & ICP-ES & 100 & 400 & 10000 \\
\hline $\mathrm{Mg}$ & ICP-ES & 200 & 500 & 10000 \\
\hline $\mathrm{Mn}$ & ICP-ES & 100 & 100 & 1000 \\
\hline Mo & ICP-MS & 100 & 100 & 1000 \\
\hline $\mathrm{Na}$ & ICP-ES & 100 & 1000 & 10000 \\
\hline $\mathrm{Nb}$ & ICP-MS & 50 & 100 & 3500 \\
\hline $\mathrm{Ni}$ & ICP-ES & 200 & 5000 & 12000 \\
\hline $\mathrm{P}$ & ICP-ES & 250 & 200 & 1000 \\
\hline $\mathrm{Pb}$ & ICP-MS & 100 & 200 & 1000 \\
\hline $\mathrm{Si}$ & ICP-ES & 150 & 200 & 200 \\
\hline Sn & ICP-MS & 100 & 100 & 2500 \\
\hline $\mathrm{Ta}$ & ICP-MS & 200 & 200 & 500 \\
\hline $\mathrm{Ti}$ & ICP-ES & 100 & 100 & 2500 \\
\hline $\mathrm{U}$ & ICP-MS & 100 & 5000 & Not provided \\
\hline $\mathrm{V}$ & ICP-MS & 5 & 300 & 2500 \\
\hline $\mathrm{W}$ & ICP-MS & 100 & 200 & 2500 \\
\hline $\mathrm{Zn}$ & ICP-ES & 100 & 150 & 1000 \\
\hline $\mathrm{Zr}$ & ICP-ES & 50 & 50 & 1000 \\
\hline $\mathrm{Gd}$ & ICP-MS & 0.5 & 3 & 250 \\
\hline $\mathrm{F}$ & $\mathrm{IC}$ & 250 & 250 & 500 \\
\hline $\mathrm{Cl}$ & IC & 250 & 250 & 500 \\
\hline $\mathrm{Ag}$ & ICP-MS & 100 & 250 & 10000 \\
\hline $\mathrm{Bi}$ & Not set up & 10 & 100 & 1000 \\
\hline $\mathrm{Co}$ & ICP-MS & 50 & 100 & 10000 \\
\hline Dy & ICP-MS & 0.5 & 1 & 1000 \\
\hline $\mathrm{Eu}$ & ICP-MS & 0.5 & 1 & 1000 \\
\hline In & Not set up & 20 & 20 & 1000 \\
\hline $\mathrm{N}$ & Not available & 300 & 400 & 400 \\
\hline $\mathrm{S}$ & ICP-ES & 250 & 250 & 1000 \\
\hline $\mathrm{Sm}$ & ICP-MS & 2 & 2 & 1000 \\
\hline Th & ICP-MS & 50 & 100 & 100 \\
\hline $\mathrm{Np}$ & ICP-MS & Not provided & 500 & Not provided \\
\hline $\mathrm{Am}$ & ICP-MS & Not provided & 7000 & Not provided \\
\hline
\end{tabular}

*Elements that are analyzed on the ICP-ES method are listed for "ICP-ES," and elements analyzed on the ICP-MS method are listed for "ICP-MS." 
The application of matrix-matched calibration standards or the method of standards addition can be used to address matrix effects. However, these approaches are not practical because of the extra accountability and safety measures needed to spike the standards with $\mathrm{Pu}$. Furthermore, there are other consequences besides matrix effects when attempting to analyze samples with up to $80 \mathrm{~g} \mathrm{Pu} / \mathrm{L}$ with minimal dilution. An example is noted on the ICP-MS method, where $\mathrm{Pu}$ carryover in the sample introduction must be washed out with $\sim 20 \% \mathrm{v} / \mathrm{v} \mathrm{HNO}_{3}$ sometimes requiring up to four hours. Another example is for ICP-ES, when the presence of potassium fluoride (KF) in these samples affects leaching of B and Si constituents from samples and reaction glassware, thereby skewing the $\mathrm{B}$ and Si measurements.

The purpose of this report is to detail an alternative analytical protocol from the typical sample dilution and analysis (i.e., "dilute and shoot") protocol on the ICP-ES and ICP-MS AD methods. With the application of $\mathrm{Pu}$ column extraction prior to analysis to eliminate the aforementioned matrix effects by removing the $\mathrm{Pu}$, it is found that the HB-Line $\mathrm{PuO}_{2} \mathrm{MOX}$ Feed Product Specifications can be met. This alternate approach utilizes an Eichrom ${ }^{\mathrm{TM}} \mathrm{RE}$ (Rare Earth) column for Pu removal, after which impurities analysis are performed on the elution product and raffinate. Due to the absence of $\mathrm{Pu}$ along with an amenable acid matrix, a significantly lower dilution factor (about two orders-of-magnitude lower) is accomplished on these sample types. The minimal dilution factor advertently drives down the method reporting limit (MRL) on the method, as shown:

$$
M R L=I R L \times \text { total } D F
$$

The instrument reporting level (IRL) is multiplied by the total dilution factor, which is a combination of the sample dissolution dilution factor (or column extraction in this case) and instrument dilution factor. The IRL is derived from the instrument's detection limit (IDL) for a given analyte accordingly:

$$
I R L=I D L \times 3.33
$$

As shown in the equation, the total dilution factor is directly proportional to the MRL, such that the lower dilution factors achievable as a result of Pu column removal help to reduce the MRL for an analyte, therefore ensuring that the ICD limits can be reached.

The IRL is the standard deviation of ten blank measurements on the ICP-ES multiplied by ten. On the ICP-MS method, the IRL is the average of the calibration blank and closing blank standard deviations multiplied by ten. The ICP-MS IRLs are calculated on a daily basis, whereas the ICP-ES IRLs are calculated at least annually. The ICP-MS determines a signal to noise ratio and transposes the number into an IRL with every use, and the ICP-ES does not and is periodically tested for detection levels. Environmental Protection Agency (EPA) method SW846 6010C (ICP-ES) states that the IDL should be established initially and then determined on an annual basis. The IRLs for most isotopes on the ICP-MS method are typically 10-ppt (parts-pertrillion), and it is found that the ICP-ES IRLs have remained relatively consistent at the lower parts-per-billion (ppb) levels for most elements. Consequently, the methods' IDLs were seen more as a constant during this method development for achieving lower MRLs, therefore placing all importance on the total dilution factor in the MRL equation.

Table 1-2 lists the analytical ICP-ES and ICP-MS IRLs and MRLs for the typical "dilute and shoot" protocol on a nominal $50 \mathrm{~g} / \mathrm{L}$ Pu solution. For most elements on the preferred method (shaded in table 1-2), it is seen that the "dilute and shoot" protocol can be applied to meet the required limits. In some cases, the limits cannot be met (\#'s in parenthesis). The Pu column 
extraction method detailed in this report accomplishes those limits that cannot be attained by normal "dilute and shoot," since the samples can be analyzed at lower dilution factors.

Table 1-2. Analytical MRLs for "Dilute and Shoot" on Nominal 50 g/L Pu Solution.

\begin{tabular}{|c|c|c|c|c|c|c|c|c|}
\hline \multirow[t]{2}{*}{ element } & \multirow{2}{*}{$\begin{array}{c}\text { Col A } \\
\text { Standard } \\
\text { limits } \mu g / g \\
P u \\
\end{array}$} & \multirow{2}{*}{$\begin{array}{c}\text { Col B } \\
\text { Desired } \\
\text { limits } \\
\mu \mathrm{g} / \mathrm{g} \mathrm{Pu}\end{array}$} & \multicolumn{2}{|c|}{ preferred method } & \multirow{2}{*}{$\begin{array}{c}\text { ICP- } \\
\text { ES } \\
M R L \\
(\mathrm{mg} / \mathrm{L}) \\
\end{array}$} & \multirow{2}{*}{$\begin{array}{c}\text { ICP-ES } \\
\text { MRL } \\
\mu g / g \text { Pu }\end{array}$} & \multirow{2}{*}{$\begin{array}{c}\text { ICP- } \\
\text { MS } \\
M R L \\
(\mathrm{mg} / \mathrm{L}) \\
\end{array}$} & \multirow{2}{*}{$\begin{array}{c}\text { ICP-MS } \\
\text { MRL } \\
\mu \mathrm{g} / \mathrm{g} \text { Pu }\end{array}$} \\
\hline & & & ICP-ES & ICP-MS & & & & \\
\hline $\mathrm{Ag}$ & 250 & 100 & & yes & & & 0.25 & 5.0 \\
\hline $\mathrm{Al}$ & 500 & 100 & yes & & 0.28 & 5.6 & & \\
\hline $\mathrm{B}$ & 100 & 1 & yes & & 0.66 & $(30)$ & & \\
\hline $\mathrm{Be}$ & 100 & 100 & yes & & 0.013 & 0.3 & & \\
\hline $\mathrm{Ca}$ & 500 & 150 & yes & & 0.25 & 5.0 & & \\
\hline $\mathrm{Cd}$ & 10 & 5 & & yes & & & 0.25 & 5.0 \\
\hline $\mathrm{Co}$ & 100 & 50 & yes & & 0.85 & 17.0 & & \\
\hline $\mathrm{Cr}$ & 1000 & 200 & yes & & 0.82 & 16.4 & & \\
\hline $\mathrm{Cu}$ & 100 & 100 & yes & & 0.63 & 12.6 & & \\
\hline Dy & 1 & 0.5 & & yes & & & 1 & (20) \\
\hline $\mathrm{Eu}$ & 1 & 0.5 & & yes & & & 1 & $(20)$ \\
\hline $\mathrm{Fe}$ & 2000 & 500 & yes & & 0.96 & 19.2 & & \\
\hline $\mathrm{Ga}$ & 12000 & 0.12 & & yes & & & 1 & $(20)$ \\
\hline $\mathrm{Gd}$ & 3 & 0.5 & yes & yes & & & 1 & $(20)$ \\
\hline $\mathrm{K}$ & 300 & 100 & yes & & 4.81 & 96.2 & & \\
\hline $\mathrm{Li}$ & 400 & 100 & yes & & 0.23 & 4.7 & & \\
\hline $\mathrm{Mg}$ & 500 & 200 & yes & & 0.15 & 3.0 & & \\
\hline $\mathrm{Mn}$ & 100 & 100 & yes & & 0.21 & 4.3 & & \\
\hline Mo & 100 & 100 & yes & & 0.99 & 19.7 & & \\
\hline $\mathrm{Na}$ & 1000 & 100 & yes & & 0.33 & 6.6 & & \\
\hline $\mathrm{Nb}$ & 100 & 50 & & yes & & & 0.25 & 5.0 \\
\hline $\mathrm{Ni}$ & 5000 & 200 & yes & & 1.6 & 32.0 & & \\
\hline $\mathrm{P}$ & 200 & 250 & yes & & 1.39 & 27.8 & & \\
\hline $\mathrm{Pb}$ & 200 & 100 & & yes & & & 0.25 & 5.0 \\
\hline$S$ & 250 & 250 & yes & & 12.5 & 250 & & \\
\hline $\mathrm{Si}$ & 200 & 150 & yes & & 1.56 & 31.2 & & \\
\hline $\mathrm{Sm}$ & 2 & 2 & & yes & & & 1 & (20) \\
\hline $\mathrm{Sn}$ & 100 & 100 & & yes & & & 0.25 & 5.0 \\
\hline $\mathrm{Ta}$ & 200 & 200 & & yes & & & 0.25 & 5.0 \\
\hline $\mathrm{Ti}$ & 100 & 100 & yes & & 0.131 & 2.6 & & \\
\hline $\mathrm{Th}$ & 100 & 50 & & yes & & & 0.25 & 5.0 \\
\hline $\mathrm{V}$ & 300 & 5 & yes & & 0.47 & $(9.4)$ & & \\
\hline $\mathrm{W}$ & 200 & 100 & & yes & & & 0.25 & 5.0 \\
\hline $\mathrm{Zn}$ & 150 & 100 & yes & & 0.919 & 18.4 & & \\
\hline $\mathrm{Zr}$ & 50 & 100 & & yes & & & 0.25 & 5.0 \\
\hline $\mathrm{U}$ & & 100 & & yes & & & 0.25 & 5.0 \\
\hline
\end{tabular}

Parenthetical (\#'s) did not meet column B limits 
The following sections describe the experimental procedures for the sample column extraction, spiked sample column extraction, ICP-MS analysis, and ICP-ES analysis. The ICP-ES and ICPMS results included in the report indicate that column extraction is a suitable method for meeting the ICD limits. Future work on both analytical methods and for other relevant matrices is recommended. 


\subsection{Experimental Procedure}

\subsection{Sample Column Extraction}

Figure 2-1 shows the sample column extraction method. The steps are also described below:

1. $400-\mu \mathrm{L}$ of $\sim 50 \mathrm{~g} / \mathrm{L} \mathrm{Pu}$ "Hearts Cut" sample was diluted $12.5 \mathrm{x}$ with $4.4-\mathrm{mL} 4 \mathrm{M} \mathrm{HNO}_{3}$, $100-\mu \mathrm{L} 4 \mathrm{M} \mathrm{NaNO}_{2}$, and $100-\mu \mathrm{L} 100 \mu \mathrm{g}$ Nd tracer. The solution was loaded onto a double stack of Eichrom ${ }^{\mathrm{TM}} \mathrm{RE}$ (Rare Earth) resin cartridges.

2. The raffinate was collected for ICP-ES and ICP-MS analysis of trace elements not retained on the columns. The raffinate sample dilution factor at this point was $12.5 \mathrm{x}$.

3. 20-mL $3 \mathrm{M} \mathrm{HCl}$ was added to the columns to elute the retained trace elements off the columns.

4. The eluent was dried down to evaporate off the $\mathrm{HCl}$ and re-dissolved in 5-mL $0.1 \mathrm{M}$ $\mathrm{HNO}_{3}$ to provide a more suitable acid matrix for ICP-ES and ICP-MS analysis. The eluent sample dilution factor at this point was $12.5 \mathrm{x}$.

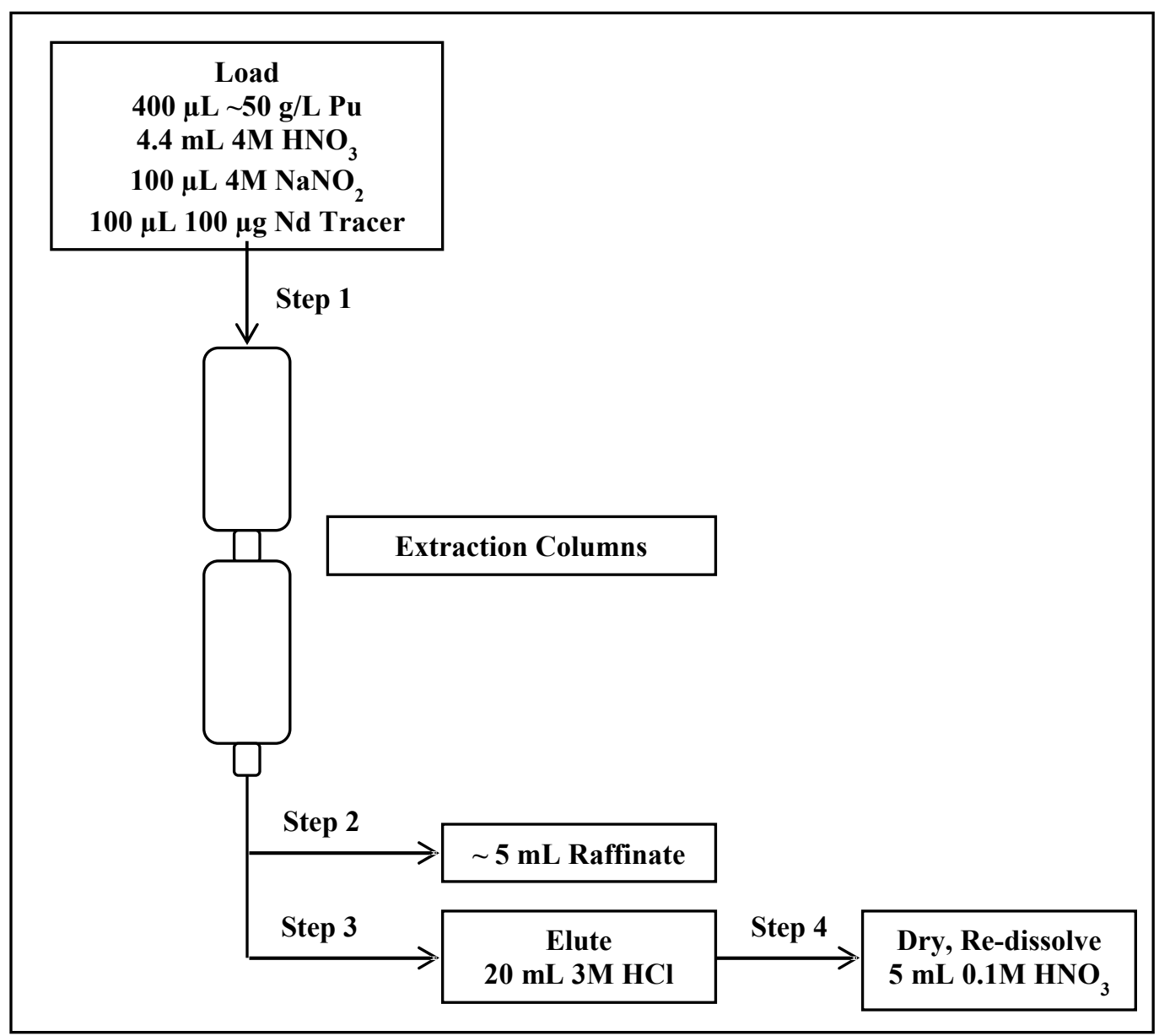

Figure 2-1. Sample Column Extraction. 


\subsection{Spiked Sample Column Extraction}

To validate the efficiency of the method, an additional "Hearts Cut" aliquot was spiked with High Purity (HP) mixed standards. Figure 2-2 shows the extraction scheme, and the steps are described below:

1. $400-\mu \mathrm{L}$ of $\sim 50 \mathrm{~g} / \mathrm{L} \mathrm{Pu}$ "Hearts Cut" sample was diluted $12.5 \mathrm{x}$ with $4.3-\mathrm{mL} 4 \mathrm{M} \mathrm{HNO}_{3}$, $100-\mu \mathrm{L} 4 \mathrm{M} \mathrm{NaNO}_{2}$, and $100-\mu \mathrm{L} 100 \mu \mathrm{g} / \mathrm{mL}$ each of High Purity Mix A and B standards. The solution was loaded onto a double stack of Eichrom ${ }^{\mathrm{TM}}$ RE (Rare Earth) resin cartridges. HP Mix A also contained Nd as the tracer.

2. The raffinate was collected for ICP-ES and ICP-MS analysis of trace elements not retained on the columns. The raffinate spiked sample dilution factor at this point was $12.5 \mathrm{x}$.

3. 20-mL $3 \mathrm{M} \mathrm{HCl}$ was added to the columns to elute the retained trace elements off the columns.

4. The eluent was dried down to evaporate off the $\mathrm{HCl}$ and re-dissolved in 5-mL $0.1 \mathrm{M}$ $\mathrm{HNO}_{3}$ to provide a more suitable acid matrix for ICP-ES and ICP-MS analysis. The eluent spiked sample dilution factor at this point was $12.5 \mathrm{x}$.

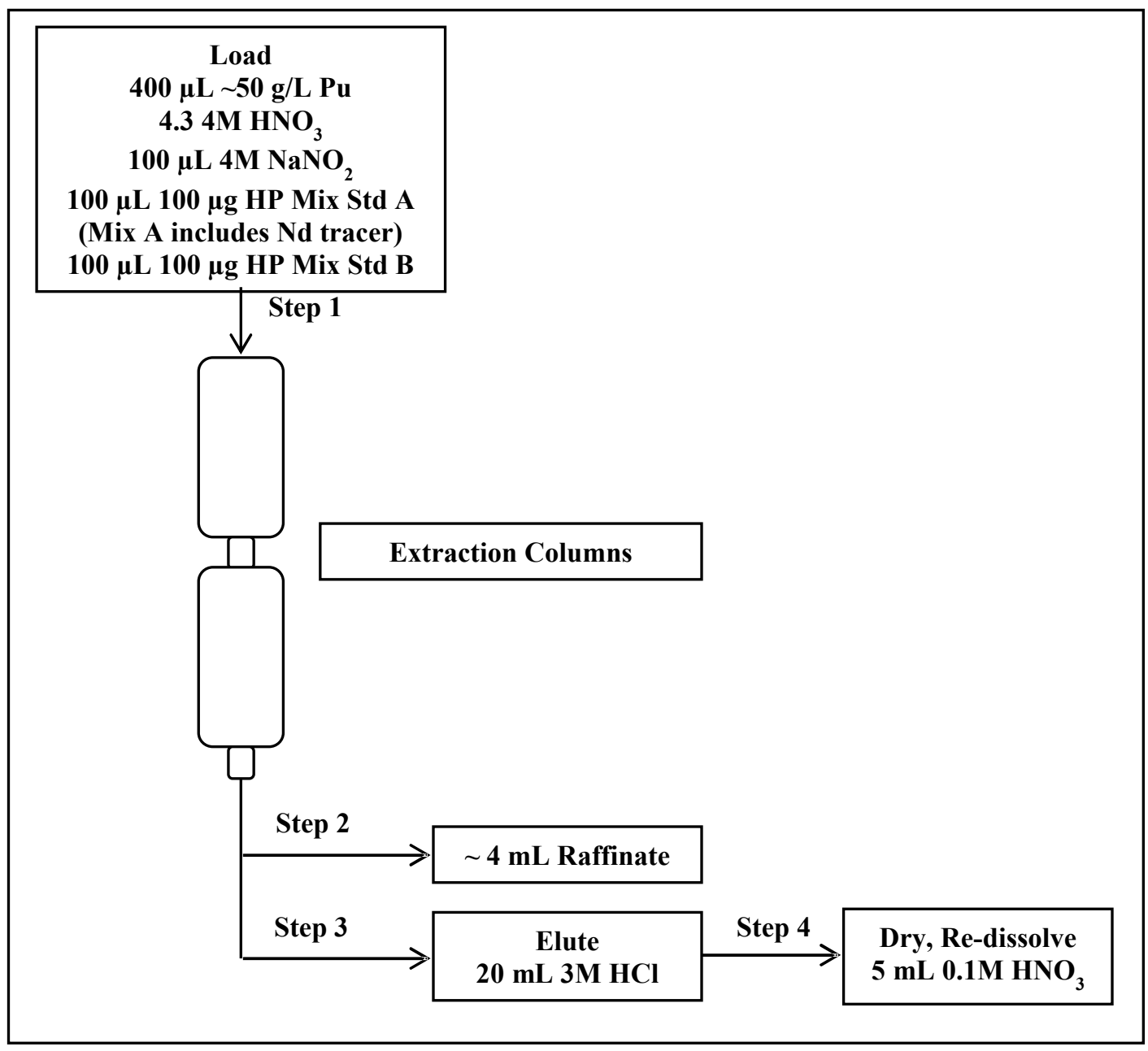

Figure 2-2. Spiked Sample Column Extraction. 
Table 2-1 lists the elements along with the associated HP standard, either Mix A or Mix B. Also included is the collection step in which the element of interest was present, either in the raffinate or the eluent of the column extraction method. Some elements remained on the column and could not be analyzed, while others were observed in both the raffinate and eluent. ICP-ES and ICPMS elements that are not in the standards but are listed on Table 1-1 are Am, Np, and S; these elements will be quantified without the extraction method.

Table 2-1. HP Standard Elements and Collection Steps

\begin{tabular}{|c|c|c|}
\hline Element & HP Standard & Collection Step \\
\hline $\mathrm{Al}$ & $\overline{\mathrm{A}}$ & Raffinate/Eluent \\
\hline $\mathrm{B}$ & $\mathrm{A}$ & Raffinate/Eluent \\
\hline $\mathrm{Be}$ & $\overline{\mathrm{A}}$ & Raffinate \\
\hline $\mathrm{Ca}$ & $\bar{A}$ & Raffinate/Eluent \\
\hline $\mathrm{Cd}$ & $\mathrm{A}$ & Raffinate \\
\hline $\mathrm{Cr}$ & $\mathrm{A}$ & Raffinate \\
\hline $\mathrm{Cu}$ & A & Raffinate \\
\hline $\mathrm{Fe}$ & A & Eluent \\
\hline $\mathrm{Ga}$ & A & Raffinate \\
\hline $\mathrm{K}$ & $\mathrm{A}$ & Raffinate \\
\hline $\mathrm{Li}$ & $\mathrm{A}$ & Raffinate \\
\hline $\mathrm{Mg}$ & $\bar{A}$ & Raffinate/Eluent \\
\hline $\mathrm{Mn}$ & $\mathrm{A}$ & Remained \\
\hline Mo & $\bar{B}$ & Remained \\
\hline $\mathrm{Na}$ & A & Raffinate \\
\hline $\mathrm{Nb}$ & $\mathrm{B}$ & Remained \\
\hline $\mathrm{Ni}$ & $\mathrm{A}$ & Raffinate \\
\hline $\bar{P}$ & $\bar{A}$ & Raffinate/Eluent \\
\hline $\mathrm{Pb}$ & $\mathrm{A}$ & Raffinate \\
\hline $\mathrm{Si}$ & $\mathrm{B}$ & Raffinate \\
\hline $\mathrm{Sn}$ & $\mathrm{B}$ & Raffinate \\
\hline $\mathrm{Ta}$ & B & Remained \\
\hline $\mathrm{Ti}$ & $\mathrm{B}$ & Eluent \\
\hline $\mathrm{U}$ & $\mathrm{A}$ & Remained \\
\hline $\mathrm{V}$ & $\mathrm{A}$ & Remained \\
\hline $\mathrm{W}$ & $\mathrm{B}$ & Raffinate \\
\hline $\mathrm{Zn}$ & $\mathrm{A}$ & Raffinate/Eluent \\
\hline $\mathrm{Zr}$ & $\mathrm{B}$ & Remained \\
\hline $\mathrm{Gd}$ & $\overline{\mathrm{A}}$ & Eluent \\
\hline $\mathrm{Ag}$ & $\mathrm{B}$ & Raffinate \\
\hline $\mathrm{Co}$ & $\mathrm{A}$ & Raffinate \\
\hline Dy & $\mathrm{A}$ & Eluent \\
\hline $\mathrm{Eu}$ & $\bar{A}$ & Eluent \\
\hline $\mathrm{Sm}$ & A & Eluent \\
\hline Th & A & Remained \\
\hline
\end{tabular}

The purpose of the RE resin is not only to strip off the high $\mathrm{Pu}$ content for the raffinate, but also to elute off the trivalent, RE elements such as Sm, Eu, Gd, and Dy at a lower dilution factor, since they have significantly lower ICD limits (see Table 1-1). Studies show that the RE resin has an affinity for rare earths out of nitric acid solutions due to the nature of the resin's material, octyl(phenyl)-N,N-diisobutylcarbamoyl-methylphosphine oxide (CMPO). ${ }^{6}$ With the addition of $4 \mathrm{M} \mathrm{NaNO}_{2}$ to oxidize the $\mathrm{Pu}$ to the 4+ state during the loading and the expectation from 
experimental studies ${ }^{6}$ that actinides are retained on the column, it should be noted that analysis of $\mathrm{U}, \mathrm{Th}, \mathrm{Np}$, and Am are not feasible for this method. However, these components have higher ICD limits when compared to the rare earths and should be measurable without an extraction method.

\subsection{ICP-MS Analysis}

The sample raffinate, sample eluent, spiked sample raffinate, and spiked sample eluent were each analyzed in triplicate for quality control purposes on the Fisons Plasma Quad II ICP-MS instrument. The calibration curves consisted of blank, 1, 10, 25, and $50 \mathrm{ppb}$ standards in $2 \% \mathrm{v} / \mathrm{v}$ $\mathrm{HNO}_{3}$ with application of $25 \mathrm{ppb}$ In and Bi internal standards. The ICP-MS method performed 2 acquisitions at 25 sweeps per acquisition for each standard and sample in the mass range of interest. The instrument dilution factors for the sample raffinate, sample eluent, spiked sample raffinate, and spiked sample eluent were respectively 10x, 20x, 100x, and 100x. For more detailed steps of the ICP-MS operation, see ADS- $1543^{4}$.

\subsection{ICP-ES Analysis}

Following ICP-MS analysis, the sample raffinate, sample eluent, spiked sample raffinate, and spiked sample eluent were analyzed on the Leeman Prodigy ICP-ES instrument. The calibration curves consisted of blank, blank, 5, and $10 \mathrm{ppm}$ standards for most elements in $2 \% \mathrm{v} / \mathrm{v} \mathrm{HNO}_{3}$ with application of $2 \mathrm{ppm} \mathrm{Sc} \mathrm{internal} \mathrm{standard.} \mathrm{The} \mathrm{ICP-ES} \mathrm{method} \mathrm{performed} 3$ integrations at 12 seconds per integration for each standard and sample on three different wavelengths per element. The instrument was set in radial mode. The instrument dilution factor was $2 \mathrm{x}$ except for the sample raffinate, which was $8 \mathrm{x}$. For more detailed steps of the ICP-ES operation, see ADS-1573. 


\subsection{Results and Discussion}

The ICP-MS results in $\mu \mathrm{g} / \mathrm{g} \mathrm{Pu}$ of the raffinate and eluent are listed on Table 3-1. The results for each mass were corrected for natural isotopic abundance to yield an elemental concentration. Also included are the ICP-MS MRLs (calculated by dividing the isotope's MRL by the isotope's natural abundance) for these samples and the required ICD column B limits. ${ }^{3}$ All results are based on an approximate concentration of $50 \mathrm{~g} / \mathrm{L} \mathrm{Pu}$ measured in a similar aliquot of the "Hearts Cut" sample. Additional masses for each element-of-interest where applicable are included to better validate the results. The HP Mix A and Mix B spike recoveries in the spiked raffinate and eluent are provided in the last column to show how well the column method worked, especially for the elution process. These spike recoveries are the true recoveries of the spiked elements from the spiked eluent sample and spiked raffinate sample, and are not corrected for the $\mathrm{Nd}$ tracer, which was also in HP Mix A.

Table 3-1. ICP-MS Results

\begin{tabular}{|c|c|c|c|c|c||}
\hline Element & $\begin{array}{c}\text { Isotope } \\
\text { Used } \\
(\mathbf{m} / \mathbf{z})\end{array}$ & $\begin{array}{c}\text { Avg. Elemental } \\
\text { Result } \\
(\boldsymbol{\mu g} / \mathbf{g} \text { Pu })\end{array}$ & $\begin{array}{c}\text { ICP-MS } \\
\text { MRL } \\
(\boldsymbol{\mu g} / \mathbf{g} \text { Pu })\end{array}$ & $\begin{array}{c}\text { ICD Col. B } \\
(\boldsymbol{\mu g} / \mathbf{g} \text { Pu) }\end{array}$ & $\begin{array}{c}\text { HP A \& HP B } \\
\text { Spike } \\
\text { Recovery (\%) }\end{array}$ \\
\hline $\mathrm{Cd}$ & 111 & 0.710 & 0.195 & 5 & 91 \\
\hline $\mathrm{Cd}$ & 112 & 0.828 & 0.100 & 5 & 93 \\
\hline $\mathrm{Cd}$ & 113 & 0.612 & 0.151 & 5 & 92 \\
\hline $\mathrm{Cd}$ & 114 & 0.804 & 0.085 & 5 & 94 \\
\hline $\mathrm{Ga}$ & 69 & 0.930 & 0.042 & 0.12 & 107 \\
\hline $\mathrm{Ga}$ & 71 & 0.681 & 0.063 & 0.12 & 110 \\
\hline $\mathrm{Pb}$ & 204 & 15.7 & 1.79 & 100 & 99 \\
\hline $\mathrm{Pb}$ & 206 & 16.4 & 0.104 & 100 & 104 \\
\hline $\mathrm{Pb}$ & 207 & 15.5 & 0.113 & 100 & 99 \\
\hline $\mathrm{Pb}$ & 208 & 15.7 & 0.048 & 100 & 103 \\
\hline $\mathrm{Sn}$ & 117 & 4.45 & 0.326 & 100 & 91 \\
\hline $\mathrm{Sn}$ & 118 & 4.28 & 0.103 & 100 & 92 \\
\hline $\mathrm{Sn}$ & 119 & 4.01 & 0.291 & 100 & 85 \\
\hline $\mathrm{Sn}$ & 120 & 4.33 & 0.076 & 100 & 91 \\
\hline $\mathrm{Co}$ & 59 & 0.369 & 0.025 & 50 & 105 \\
\hline $\mathrm{Gd}$ & 155 & 9.31 & 0.169 & 0.5 & 55 \\
\hline $\mathrm{Gd}$ & 156 & 9.66 & 0.122 & 0.5 & 54 \\
\hline $\mathrm{Gd}$ & 157 & 9.05 & 0.159 & 0.5 & 56 \\
\hline $\mathrm{Dy}$ & 163 & 0.403 & 0.100 & 0.5 & 55 \\
\hline $\mathrm{Eu}$ & 151 & 0.077 & 0.052 & 0.5 & 54 \\
\hline $\mathrm{Eu}$ & 153 & 0.119 & 0.048 & 0.5 & 54 \\
\hline $\mathrm{Sm}$ & 147 & 0.424 & 0.167 & 2 & 54 \\
\hline $\mathrm{Sm}$ & 149 & 0.218 & 0.181 & 2 & 55 \\
\hline $\mathrm{Sm}$ & 152 & 0.292 & 0.093 & 2 & 56 \\
\hline & & & & & \\
\hline \hline
\end{tabular}

In the case of the raffinate, the elements recovered in the $85-110 \%$ range. Most important is that while all results are positive, all masses have RLs that are below the required ICD limits for the raffinate due to the low dilution factor. While one purpose for this method was to attempt clean up a Pu sample for ICP-MS analysis of $\mathrm{V}$ in the raffinate, the method was unsuccessful since V remained on the column. Further attempts on the ICP-MS method should be made with the straight $\mathrm{Pu}$ "Hearts Cut" sample by ICP-MS for V. 
The assessment of the rare earth elements ( $\mathrm{Gd}, \mathrm{Dy}, \mathrm{Eu}$, and $\mathrm{Sm}$ ) in the eluent was imperative because of the low ICD requirements shown on Table 3-1. The HP Mix A and Mix B spike recoveries were approximately $50 \%$ as was also observed for the $\mathrm{Nd}$ tracer. Positive results were measured at the selected masses. It should be noted that higher recoveries could have been achieved, but this would have jeopardized the raffinate, in which the Ga required a minimal dilution factor. Table 3-2 shows the HP A and B spike recoveries after correcting for the $\mathrm{Nd}$ tracer, and all recoveries are within $94-98 \%$. The Gd results are in agreement for the $+/-20 \%$ method, but the Eu and Sm results obviously show greater scatter. Nevertheless, these results along with the Dy-163 mass results are all below the required ICD limits. The ICP-MS MRLs at the low dilution factor show that the ICD limits are not exceeded.

Table 3-2. ICP-MS Results in the Eluent Corrected for Nd Tracer.

\begin{tabular}{||c|c|}
\hline \hline Element/Mass & $\begin{array}{c}\text { HP A \& HP B Spike } \\
\text { Recovery (\%) } \\
\text { Nd Tracer Corrected }\end{array}$ \\
\hline Gd-155 & 96 \\
\hline Gd-156 & 94 \\
\hline Gd-157 & 98 \\
\hline Dy-163 & 96 \\
\hline Eu-151 & 94 \\
\hline Eu-153 & 94 \\
\hline Sm-147 & 94 \\
\hline Sm-149 & 96 \\
\hline Sm-152 & 98 \\
\hline
\end{tabular}

Table 3-3 lists the ICP-ES results in $\mu \mathrm{g} / \mathrm{g}$ Pu of the raffinate and eluent. Also included are the calculated ICP-ES MRLs; the MRLs are the same for most elements since the actual results were not detectable. The last two columns list the ICD column B limits and HP Mix A and B spike recoveries. Analogous to the ICP-MS results, the results are based on an approximate concentration of $50 \mathrm{~g} / \mathrm{L} \mathrm{Pu}$ measured in a similar aliquot of the "Hearts Cut" sample.

Table 3-3. ICP-ES Results

\begin{tabular}{|c|c|c|c|c||}
\hline Element & $\begin{array}{c}\text { Result } \\
(\boldsymbol{\mu g} / \mathbf{g} \text { Pu })\end{array}$ & $\begin{array}{c}\text { ICP-ES MRL } \\
(\boldsymbol{\mu g} / \mathbf{g} \text { Pu })\end{array}$ & $\begin{array}{c}\text { ICD Col. B } \\
(\boldsymbol{\mu g} / \mathbf{g} \text { Pu) }\end{array}$ & $\begin{array}{c}\text { HP A \& HP B } \\
\text { Spike } \\
\text { Recovery (\%) }\end{array}$ \\
\hline $\mathrm{Be}$ & $<1.60$ & 1.60 & 100 & 97 \\
\hline $\mathrm{Cd}$ & $<6.20$ & 6.20 & 5 & 93 \\
\hline $\mathrm{Co}$ & $<17.0$ & 17.0 & 50 & 90 \\
\hline $\mathrm{Cr}$ & $<20.4$ & 20.4 & 200 & 105 \\
\hline $\mathrm{Cu}$ & $<43.0$ & 43.0 & 100 & 104 \\
\hline $\mathrm{Fe}$ & 170 & 3.15 & 500 & 50 \\
\hline $\mathrm{Gd}$ & $<10.8$ & 10.8 & 0.5 & 50 \\
\hline $\mathrm{K}$ & $<602$ & 602 & 100 & 125 \\
\hline $\mathrm{Li}$ & $<29.2$ & 29.2 & 100 & 100 \\
\hline $\mathrm{Ni}$ & $<91.0$ & 91.0 & 200 & 104 \\
\hline $\mathrm{Pb}$ & $<143$ & 143 & 100 & 105 \\
\hline $\mathrm{Sn}$ & $<112$ & 112 & 100 & 87 \\
\hline $\mathrm{Ti}$ & $<1.90$ & 1.90 & 100 & 48 \\
\hline
\end{tabular}


The raffinate MRLs are elevated since it was analyzed with an $8 \mathrm{x}$ instrument dilution factor, as there was limited sample volume. The HP Mix A and Mix B spike recoveries varied and were within $50-125 \%$. In most cases the extracted analyte MRL's were lower than either ICD Column A or B limits. However, a majority of the limits may be achieved by routine dilute and shoot protocol. Several analyte limits were not achieved (e.g. Cd, Sn, Pb, and $\mathrm{Gd}$ ) by either one or both protocols, and these elements will be analyzed by mass spectrometry. The potassium MRL, by extraction, exceeded both limits, and by dilute/shoot (see Table 1-2) is noted to be borderline for ICD Column B limit. Therefore, potassium may be performed by atomic absorption spectroscopy (AA) if needed. ICP-ES spike recoveries for HP Mix A and Mix B were similar to those run by ICP-MS. 


\subsection{Conclusions}

The results presented in this report document the potential success of the RE resin column extraction application on highly concentrated $\mathrm{Pu}$ samples to meet MOX feed product specifications. The original "Hearts Cut" sample required a 10000x dilution to limit instrument drift on the ICP-MS method. The instrument dilution factors improved to $125 \mathrm{x}$ and $250 \mathrm{x}$ for the sample raffinate and sample eluent, respectively. As noted in the introduction, the significantly lower dilutions help to drop the total MRL for the analyte. Although the spike recoveries were half of expected in the eluent for several key elements, they were between $94-98 \%$ after $\mathrm{Nd}$ tracer correction. It is seen that the lower ICD limit requirements for the rare earths are attainable because of less dilution. Especially important is the extremely low Ga limit at $0.12 \mu \mathrm{g} / \mathrm{g} \mathrm{Pu}$; an ICP-MS method is now available to accomplish this task on the sample raffinate. While B and V meet the column A limits, further development is needed to meet the column B limits. Even though $\mathrm{V}$ remained on the RE resin column, an analysis method is ready for investigation on the ICP-MS, but it does not mean that V cannot be measured on the ICP-ES at a low dilution to meet the column B limits. Furthermore, this column method can be applicable for ICP-ES as shown in Table 3-2, in that it trims the sample of $\mathrm{Pu}$, decreasing and sometimes eliminating $\mathrm{Pu}$ spectral interferences.

Table 4-1 summarizes AD methods targeting ICD column limits. 
Table 4-1. Analytical summary methods to meet ICD limits (on nominal $50 \mathrm{~g} / \mathrm{L}$ Pu solution).

\begin{tabular}{|c|c|c|c|c|c|c|}
\hline \multirow[t]{2}{*}{ Element } & \multirow[t]{2}{*}{$\begin{array}{c}\text { Col A } \\
\text { limits } \mu g / g \text { Pu }\end{array}$} & \multirow[t]{2}{*}{$\begin{array}{l}\text { Col B limits } \\
\mu g / g \text { Pu }\end{array}$} & \multicolumn{4}{|c|}{$\begin{array}{l}\text { Preferred method }(A=\text { meets column } A \text { spec }),(B=\text { meets } \\
\text { column B spec })(X=\text { not meeting at this time })\end{array}$} \\
\hline & & & ICP-ES & ICP-MS & $\begin{array}{l}\text { ICP-MS } \\
(+ \text { column })\end{array}$ & (text below) \\
\hline Ag (Silver) & 250 & 100 & & $\mathrm{~A}, \mathrm{~B}$ & & \\
\hline $\mathrm{Al}$ (Aluminum) & 500 & 100 & $\mathrm{~A}, \mathrm{~B}$ & & & \\
\hline B (Boron) & 100 & 1 & $\mathrm{~A}$ & & & \\
\hline Be (Beryllium) & 100 & 100 & $\mathrm{~A}, \mathrm{~B}$ & & & \\
\hline Bi (Bismuth) & 100 & 10 & & & & $\mathrm{X}$ \\
\hline $\mathrm{C}$ (Carbon) & 1000 & 500 & & & & $\mathrm{X}$ \\
\hline $\mathrm{Ca}$ (Calcium) & 500 & 150 & $\mathrm{~A}, \mathrm{~B}$ & & & \\
\hline Cd (Cadmium) & 10 & 5 & & $\mathrm{~A}, \mathrm{~B}$ & & \\
\hline $\mathrm{Cl}$ (Chlorine) & 250 & 250 & & & & $\mathrm{X}$ \\
\hline Co (Cobalt) & 100 & 50 & A,B & & & \\
\hline $\mathrm{Cr}$ (Chromium) & 1000 & 200 & $\mathrm{~A}, \mathrm{~B}$ & & & \\
\hline $\mathrm{Cu}$ (Copper) & 100 & 100 & $\mathrm{~A}, \mathrm{~B}$ & & & \\
\hline Dy (Dysprosium) & 1 & 0.5 & & & $\mathrm{~A}, \mathrm{~B}$ & \\
\hline Eu (Europium) & 1 & 0.5 & & & $\mathrm{~A}, \mathrm{~B}$ & \\
\hline F (Fluorine) & 250 & 250 & & & & $\mathrm{X}$ \\
\hline Fe (Iron) & 2000 & 500 & $\mathrm{~A}, \mathrm{~B}$ & & & \\
\hline Ga (Gallium) & 12000 & 0.12 & & & $\mathrm{~A}, \mathrm{~B}$ & \\
\hline Gd (Gadolinium) & 3 & 0.5 & & & $\mathrm{~A}, \mathrm{~B}$ & \\
\hline In (Indium) & 20 & 20 & & & & $\mathrm{X}$ \\
\hline K (Potassium) & 300 & 100 & $\mathrm{~A}, \mathrm{~B}$ & & & \\
\hline Li (Lithium) & 400 & 100 & $\mathrm{~A}, \mathrm{~B}$ & & & \\
\hline Mg (Magnesium) & 500 & 200 & $\mathrm{~A}, \mathrm{~B}$ & & & \\
\hline Mn (Manganese) & 100 & 100 & $\mathrm{~A}, \mathrm{~B}$ & & & \\
\hline Mo (Molybdenum) & 100 & 100 & $\mathrm{~A}, \mathrm{~B}$ & & & \\
\hline N (Nitrogen) & 400 & 300 & & & & $\mathrm{X}$ \\
\hline $\mathrm{Na}$ (Sodium) & 1000 & 100 & A,B & & & \\
\hline $\mathrm{Nb}$ (Niobium) & 100 & 50 & & $\mathrm{~A}, \mathrm{~B}$ & & \\
\hline Ni (Nickel) & 5000 & 200 & $\mathrm{~A}, \mathrm{~B}$ & & & \\
\hline P (Phosphorus) & 200 & 250 & $\mathrm{~A}, \mathrm{~B}$ & & & \\
\hline $\mathrm{Pb}($ Lead $)$ & 200 & 100 & & $\mathrm{~A}, \mathrm{~B}$ & & \\
\hline S (Sulfur) & 250 & 250 & $\mathrm{~A}, \mathrm{~B}$ & & & \\
\hline Si (Silicon) & 200 & 150 & $\mathrm{~A}, \mathrm{~B}$ & & & \\
\hline Sm (Samarium) & 2 & 2 & & & $\mathrm{~A}, \mathrm{~B}$ & \\
\hline Sn (Tin) & 100 & 100 & & $\mathrm{~A}, \mathrm{~B}$ & & \\
\hline Ta (Tantalum) & 200 & 200 & & $\mathrm{~A}, \mathrm{~B}$ & & \\
\hline Ti (Titanium) & 100 & 100 & $\mathrm{~A}, \mathrm{~B}$ & & & \\
\hline Th (Thorium) & 100 & 50 & & $\mathrm{~A}, \mathrm{~B}$ & & \\
\hline V (Vanadium) & 300 & 5 & $\mathrm{~A}$ & & & \\
\hline W (Tungsten) & 200 & 100 & & $\mathrm{~A}, \mathrm{~B}$ & & \\
\hline Zn (Zinc) & 150 & 100 & $\mathrm{~A}, \mathrm{~B}$ & & & \\
\hline $\mathrm{Zr}$ (Zirconium) & 50 & 100 & & $\mathrm{~A}, \mathrm{~B}$ & & \\
\hline U (Uranium) & & 100 & & $\mathrm{~A}, \mathrm{~B}$ & & \\
\hline
\end{tabular}

Bi \& In are ICP-MS internal standards

$\mathrm{Cl} \& \mathrm{~F}$ to be analyzed in post calcined product

$\mathrm{C} \& \mathrm{~N}$ by solids analyzer

B \& V meet A spec, but not B spec, may need further development 


\subsection{Recommendations for Future Work}

The following recommendations are based upon results in this report.

- This data represents a single experiment for the application of the RE column extraction method. More work on this method is needed to validate the observations. This added testing also includes use of additional sample volumes for the ICP-ES method to better validate the application.

- The low limit for B (see Table 1-1) will require additional testing. Since B showed up in both the raffinate and eluent, either a method on the Plasma Quad II or Agilent 7700x ICP-MS instrument is needed for further evaluation.

- V remained on the RE column. Consequently, further testing on the straight "Hearts Cut" sample is recommended to ensure its limit is attainable on the ICP-ES. Also, method validation is suggested on the ICP-MS method.

- S was not tested during this application. The ICP-ES method proposes, based on previous testing, an instrument dilution factor at 16x on the straight "Hearts Cut" sample to meet the ICD limit. 


\subsection{References}

1. E.A. Kyser, "Task Technical and Quality Assurance Plan for Plutonium Anion Exchange Flowsheet for HB-Line", SRNL-RP-2011-01598, Rev. 0.

2. M.L Crowder, "Task Technical and Quality Assurance Plan for Precipitation and Calcination of Plutonium (IV) Oxalate to Form Plutonium Oxide and Subsequent Gas Generation Studies to Support the MOX Feed Mission", SRNL-RP-2011-01657, Rev. 0.

3. E.A. Kyser, "Impurities for Anion Exchange Testing - Pu to MOX", SRNL-L3100-201100234, Rev. 0.

4. L.C. Johnson, "Inductively Coupled Plasma-Mass Spectrometer Elemental and Isotopic Analysis for Aqueous Liquid Samples PlasmaQuad II RADICPMS", ADS Procedure ADS-1543, Rev. 5.

5. M.A. Jones, "Radioactive and Non-Radioactive Sample Analysis on the Leeman Prodigy Inductively Coupled Plasma Emission Spectrometer", ADS Procedure ADS-1573 Rev. 2.

6. E.A. Huff, "TRU-Spec and RE-Spec Chromatography: Basic Studies and Applications", $34^{\text {th }}$ ORNL/DOE Conference On Analytical Chemistry in Energy Technology", Gatlinburg, TN, 1993. 


\section{Distribution:}

P. Andrews, 704-2H

M. J. Barnes, 773-A

K. P. Burrows, 704-2H

J. W. Christopher, 704-2H

M. L. Crowder, 773-A

W. G. Dyer, 704-2H

S. D. Fink, 773-A

K. J. Gallahue, 221-H

C. W. Gardner, 704-2H

B. J. Giddings, 786-5A

V. D. Jones, 772-F

W. D. King, 773-42A

E. A. Kyser, 773-A

S. L. Marra, 773-A

W. L. Melton, 707-F

R. A. Pierce, 773-A

T. S. Rudisill, 773-A

J. B. Schaade, 704-2H

J. E. Therrell, 704-2H

S. A. Thomas, 703-46A 